Article

\title{
Business Students’ Conceptions of Sustainability
}

\author{
Anna Reid*, Peter Petocz and Paul Taylor \\ Macquarie University, North Ryde, NSW 2109, Australia; E-Mails: Peter.Petocz@mq.edu.au (P.P.); \\ Paul.Taylor@mq.edu.au (P.T.)
}

* Author to whom correspondence should be addressed; E-Mail: Anna.Reid@mq.edu.au; Tel.: +61-2-98509780; Fax: +61-2-98509776.

Received: 14 August 2009 / Accepted: 15 September 2009 / Published: 16 September 2009

\begin{abstract}
In the field of higher education, the role of sustainability is increasingly seen as an important capability of successful graduates, one of a group of higher-level dispositions that is particularly important for students' future professional roles. Discussion of sustainability often assumes that all participants understand the term in the same way, and different understandings can make meaningful dialogue difficult. This article presents an empirical investigation of the ways in which students from a business faculty at a large metropolitan university view sustainability in the specific context of their tertiary education. While some students viewed the notion in quite naïve ways-for example, the idea of 'keeping themselves going'-others talked about much broader views incorporating ideas of inter-generational justice. Investigation of such views provides important evidence for dialogue on sustainability with the next generation of professional leaders in business.
\end{abstract}

Keywords: higher education; conceptions; graduate dispositions; professional preparation

\section{Introduction}

We are currently in the middle of the United Nations Decade of Education for Sustainable Development (2005-2014). The goal of this initiative is "to integrate the principles, values and practices of sustainable development into all aspects of education and learning” by utilising a continuing educational effort to "encourage changes in behaviour that will create a more sustainable future in terms of environmental integrity, economic viability, and a just society for present and future generations" (according to statements from the UN's ESD website [1]). Back in 2002, in proposing the 
Decade of Education for Sustainable Development, the participants at the Johannesburg Earth Summit made it clear that sustainable development should be located in all educational and disciplinary domains, making statements [2] such as: "education is critical for promoting sustainable development" (article 116) and recommending to "integrate sustainable development into educational systems at all levels of education in order to promote education as a key agent for change” (article 121).

In the field of higher education, the role of sustainability is increasingly seen as an important facet of the knowledge and behaviour of successful graduates. Indeed, sustainability can be regarded as one of a group of higher-level graduate dispositions (including, for instance, creativity, ethics and crosscultural sensitivity), all of which will play an important role in students' professional work. These attributes could be considered as cross-disciplinary or 'generic skills' from the universities' pedagogical and curriculum perspectives, to be addressed as part of every student's learning program. Yet, far from being integrated into educational systems as recommended by the United Nations, sustainability often seems to be perceived in a much more limited way as the domain of environmental educators. This focus is problematic as it implies that a certain group of students, those in closely allied areas, will benefit from a targeted pedagogy whilst others, more on the periphery, will only experience such pedagogy tangentially.

At the tertiary level, various universities have set up groups with a specific focus on sustainability and sustainable development, for example, in Australia, Macquarie University's Graduate School of the Environment. At a national level, governments are also supporting the broadening of reach: for example, the UK Government [3] states that “we need to make 'sustainability literacy' a core competency for professional graduates” (p. 39). Nevertheless, the process of moving sustainability to a more central position in tertiary studies has been a long and as yet incomplete affair, despite the inclusion of sustainability on lists of 'generic skills' or 'graduate capabilities' at many universities. Universities that adopt the generic skills or graduate capability approaches focus on the inclusion of aspects of sustainability across the broad curriculum, taught from a range of different perspectives. In this way, some students are able to access different views of sustainability, but generally experience it in a rather ad hoc manner. However, it would be wrong to imply that students' only access to knowledge and action for sustainability was within formal learning venues. Students develop their views, attitudes and approaches to sustainability through interactions with family, social groups, school activity, media, computer networking and so on [4,5]. However, it is important to emphasise the role that the UN [2] has placed on formal learning situations and consider how the notion of sustainability is experienced and acted on from within the academy.

Various views of sustainability can be found in the literature. For example, in a commentary on the first editorial of this journal, Curran [6] writes: "Sustainability is a destination that we aspire to reach with the selection of the sustainable pathways that we choose as we proceed along the journey” (p. 6). In a more recent article in the same journal, Ansari and Stibbe [7] focus on the educational aspects. They discuss the notion of 'sustainability literacy', explaining that it represents a step beyond 'education about sustainability' to 'education for sustainability'. They investigate 'the skills, attributes, competencies, and dispositions to help learners and practitioners navigate their way in the challenging conditions of the twenty first century and contribute to a more sustainable society” (p. 426). A recent edited volume by Docherty, Kira and Shani [8] discusses sustainability in the context of a variety of types of work systems: "Sustainability is most often defined as a general worldview 
according to which people should strive to fulfill their needs in a manner such that the ability of future generations to fulfil their needs is not endangered (World Commission of Environment and Development, 1987). Sustainability in this sense means protecting the richness of the world's resources in such a way that their utilization does not destroy them but rather leaves equal opportunity to future generations to benefit from them as well. The sustainability concept has thus a value dimension stating that no population has the right to devour the world's resources for the satisfaction of its needs-much less its wants and ambitions” (p. 3).

Such statements explicating the notion of sustainability, some dating back over 30 years to the Brundtland Commission (as the World Commission of Environment and Development is sometimes known), would imply that there is generally a clear understanding of the meaning of the term, at least in an educational context. However, previous research with university lecturers [9] showed clearly that they had a range of conceptions about the meaning of the term sustainability. The present study adds to this by explicating the range of views that students hold about the concept. The assumption that university academics and their students share an understanding of the term, and hence can integrate the principles expounded by the United Nations into all areas of higher education, does not yet seem to be a reality. Rather, students and academics express a range of different ways of understanding sustainability that may be related to their private lives [10], or to the pedagogical context and the discipline area [11]. In the sections that follow we examine the experience of a particular cohort group of students. The selected group, business students, has the potential to contribute to world-wide sustainability in their future professional work. At the study site, business students represent the largest single group in the university, a situation that is common in most developed countries. Knowing how this particular group relates the notion of sustainability gleaned from their life world and formal studies may provide educators with a better appreciation of the pedagogical work yet to be done.

\section{Theoretical Approach}

Our study aimed to explore the different ways in which students understand sustainability in the context of their business studies and their perceived future professional roles. An important feature of the approach is that it allowed them to come up with their own definitions of the term, rather than supplying a definition from the literature (such as the one given earlier from Docherty et al. [8]) or the researchers' point of view, and to explore their own ideas about sustainability. An appropriate theoretical and methodological background for such an investigation is phenomenography [12]. Phenomenography is a qualitative and descriptive research approach that aims to investigate empirically how people experience, understand and ascribe meaning to a specific situation or phenomenon in the world around them. The approach views each person's experience as an internal relation between the subject and the object, in other words, between the participant and the phenomenon. The outcome of a phenomenographic study is a hierarchical set of qualitatively different but logically related categories, known as conceptions. These conceptions and the relations between them provide the outcome space for the phenomenon. They can be described in order of their inclusivity and sophistication, from the narrowest and most limited to the broadest and most inclusive.

This approach is somewhat different from other qualitative analytic approaches as it focuses on the nature of differences or variation between one way of experiencing or understanding something from 
another. Other methods, such as thematic analysis [13] (used to determine an exhaustive range of themes), grounded theory [14] (used to develop an understanding of ways of doing things within social settings), or action research [15] (often used for education for sustainability as a means of learning through doing), all illuminate different aspects available from the data. In the case of this study the conceptions represent ways of thinking about a phenomenon that are qualitatively distinct from each other (and hence, not a continuum). As Meyer and Land [16] suggest, once a person is aware of the more inclusive conceptions, there is no going back. The categories defined in this paper describe various conceptions of sustainability-qualitatively different ways of understanding the notion of sustainability. Each conception is derived from ideas expressed by individuals. However, it is the structure of the variation across the group that emerges through iterative readings of individuals' experience and provides the description of their conceptions of sustainability.

Phenomenography has often been used to describe people's experience of a learning and/or teaching situation $[17,18]$ or their experience of an academic discipline. For instance, Hazel and Prosser [19] looked at variation in the way students understood photosynthesis, Davies and Reid [20] looked at the way students and teachers of design understood the discipline of design, Reid and Petocz [21] looked at students' conceptions of statistics, and Reid et al. [22] looked at variation in the way that mathematics students understood mathematics. Phenomenographic research in environmental education $[23,24]$ has shown that primary and secondary school children and people in the general community understand the environment, and their relationship with the environment, in limiting and expansive ways. Interestingly, the three groups showed a similar range of conceptions. Other studies have looked at people's experience of various 'graduate capabilities', such as students' and teachers' experience of internationalisation [25,26], or areas of professional work, such as students' and practitioners' experience of accounting practice [27,28]. Each of the studies referred to in this paragraph has been used as the basis for curriculum change towards more student-focused learning environments. In phenomenographic studies, data are usually collected through a series of in-depth, open-ended interviews that focus on allowing each person to describe their experience fully [29,30]: this was the method used in this study for data collection.

\section{The Empirical Evidence}

The data on which this investigation is based were collected at Macquarie University in Sydney, Australia as part of a study investigating domestic and international students' views of professional dispositions that they develop through their studies in preparation for their future workplaces. The students were all undertaking a business degree, either on the main campus in the Division of Economic and Financial Studies (EFS, since renamed the Faculty of Business and Economics) or at the International College of Management, Sydney (ICMS, an independent institution allied to Macquarie University and teaching business courses from the same curriculum-and sometimes with the same lecturers). We avoided students in their first or last years of their degree in order to talk to people who were somewhere in the middle of their studies. Most of the international students were from countries in the Asia-Pacific region, though some were from Europe and the United States. The domestic students were equally diverse, and many of them were from Asian backgrounds. The project was designed to explore business students' views of creativity, ethics, sustainability and cross-cultural 
understanding, though in this paper the focus is on their conceptions of sustainability and its use in their future professions.

Students were recruited by placing advertisements in student newsletters and notice boards, and by making announcements in large lectures. The details of the study were approved by the appropriate ethics committee and each student gave their informed consent to participate. Interviews were carried out with a total of 44 students: about one-third (15) of them were female and two-thirds (29) male, half of them (22) were domestic and half (22) international students, just over half (23) were from the main campus (EFS) and the rest (21) from ICMS. Students were given the option to participate using an e-mail interview, an individual face-to-face interview or a group interview: around one-quarter took each of the first options (10 and 12 students), while the remaining half (22 students) were interviewed face-to-face in groups of two to four. In such group interviews, each student was asked the same main questions in turn, and then any follow-up questions, so individuals' views could be distinguished (although, of course, they could be influenced by other participants in their group). A total of 88,000 words of transcript (and e-mail records) was obtained for the 44 interviews. Here, the focus is specifically on what respondents said in answer to the questions: 'How do you understand the idea of sustainability?' and 'What role do you think sustainability will play in your future professional work?' These questions were followed, if necessary, with further probing questions: general ones such as 'Can you elaborate on that?' or specific ones such as 'Could you give me an example of how in your work you would further conservation of the environment or facilitate sustainability?'

The data were analysed in two stages. A preliminary examination of the transcripts was used to identify thematic categories for students' views of sustainability (and the other dispositions): these have been reported earlier [31]. The main analysis, reported here, investigated the qualitatively different ways that students viewed sustainability using a phenomenographic approach, as described in the previous section. The first step in such an analysis consisted of careful and repeated reading of the whole body of transcripts. Different conceptions of sustainability were suggested by each author and checked against those suggested by others before coming to a consensus. The transcripts were then reviewed to identify quotations that would support each of the conceptions identified, and the overall structure of the outcome space was confirmed.

\section{Conceptions of Sustainability}

Students' discussion of sustainability showed a range of views about the nature of sustainability itself. Irrespective of the particular view, sustainability was sometimes discussed in the context of (their and others') daily life experiences, and sometimes in the context of their business studies and their future professional work in the world of business. These two aspects, the nature of sustainability and the context of sustainability, or as Marton and Booth [12] say, the 'what' and the 'how' (technically referred to as the referential and structural dimensions of a phenomenon) are component parts of the entire conception of sustainability.

The phenomenographic analysis revealed three qualitatively different conceptions of sustainability that were shown by the participants in our study. These conceptions can be labeled as (1) Distance, (2) Resources and (3) Justice, from the narrowest and most limited to the broadest and most inclusive. They will be described in more detail in the following paragraphs, and supported by direct quotations 
from interview transcripts or e-mails (all names quoted are pseudonyms rather than students' real names).

\subsection{Distance}

In the most limited conception, students approach the idea of sustainability via a definition, maybe a dictionary definition of 'keeping something going' (maybe themselves or a business), but essentially to keep the concept at a distance and avoid any further engagement with it. Some students needed to have the word translated before talking about it, and several limited their discussion to this notion.

The following quotations illustrate this conception of sustainability. Adam treats the term as a 'buzz word' barely implying a definition, while Liz, Diane and Peter give simple definitions, in the latter cases set in the work situation and highlighting specific aspects of work sustainability (keeping up to date, maintaining staff efficiency). Sid begins with a definition in a business context that he then broadens to incorporate a personal dimension.

Adam: Sustainability. Ooh. Sort of like the catch-it's going to be the catchword for the next, you know, couple of decades.

Liz: Sustainability? Well, if I use the literal translation of the word, sustainability for, to me would mean, yeah, just longevity or something like being able to, sustainability, just being able to, you know, hang in there.

Diane: Keeping things afloat. Sustainability with yourself being able to keep up to date, especially if you're going into the workplace. ... If you're not sustainable, if you're not going to take that extra bit to be in the loop, you're going to lose out, you're going to fall behind.

Peter: And sort of cutting down on staff, making the staff that you have more efficient, finding new ways of doing things to become more efficient, is probably the right thing to do in the service industry. That's what I see as sustainability.

Sid: Sustainability to me is to be able to keep to your mission and your strategy in the company and sustain a position and growth in the market. To sustain your, your growth as well, as I said and I don't think it just has to do with companies. It has to do with all aspects of life I guess. Just to keep to your set goals and what you want to achieve.

In each of these quotes, the focus is on some form of definition of (some aspect of) sustainability, essentially designed to avoid further investigation, problematisation or connection with the notion.

\subsection{Resources}

In a broader conception, students approach the notion of sustainability by focusing on resources needed-labour, markets, environmental resources-particularly for the purposes of keeping a business going. In a more general context, people talk about material (minerals, water, soil), biological (fish, crops) or human (minority languages, populations, economies) resources.

Kitty presents the basic features of the resources conception, while Erica illustrates various aspects clearly, contrasting the use of two different types of energy.

Kitty: Basically in a business/commercial sense they are referring to probably acting in the best interest of society and reflecting environmental concerns about pollution, waste disposal and scarce 
resources in their bottom line. ... In an economic sense sustainability might touch on the concept of scarce resources and the interaction between demand and supply for certain resources.

Erica: Ok, sustainability to me is finding a way to be able to meet your objectives, but the way that you achieve your objectives should, the way that you achieve your objectives should be able to be repeated continuously and forever, I guess. So sustainability is being able to ensure the long-term survival of whatever it is you're doing. ... So if you're a company that relies on coal sources for your energy then you can't say that that's a sustainable way of operating because at the end of the day the coal sources are going to run out. So it's not a sustainable way of doing something, but if your energy sources are from the sun, then you could say well we, our operations are sustainable because we could practically keep doing this forever because the sun is always going to be, well, you know, you know it's going to be around for at least another million or so years. So that to me is sustainability, the ability to continuously do what you're doing into the future.

Fred's comments might be better used to illustrate the distance view, except for the fact that he includes an inchoate awareness of environmental aspects (set in a competitive business context).

Fred: I think that there's going to be a lot of money to be made in the whole sustainability idea of making the workplace greener, being more environmentally cautious and things like that. So I'd say there'd be a lot of money to be made in that but I don't know how essential it is.

In each of these quotes, the focus is on the utilisation of resources, particularly in the context of the participants' business setting.

\subsection{Justice}

In the broadest conception, sustainability is approached by focusing on the notion of 'fairness' from one generation to following ones. The idea is that sustainability can only occur under these conditions. In a business context, students talk about 'what a company must give up in order to keep going'.

Samantha starts with a classic definition, that she may indeed have learned in classes, but then shows her understanding of the justice aspects. Dan and Casey each begin with the resources idea and then add the inter-generational viewpoint: Tim expands on this with a more detailed example.

Samantha: Meeting the needs of the present without compromising the ability of future generations to meet their own needs. ... Basically taking the future into account. Knowing what you do will affect the future so you have to find alternative ways to do things that will benefit the future not put it in a compromising situation.

Dan: I guess my first thoughts are towards ecological sustainability, the environment, the greenhouse effects, yeah. Just, I guess that's linking directly to in a sense of the world that we leave behind for our children, future generations, and yeah. I think it's an important concept.

Casey: Well, I always put sustainability with environment. Or ecological sustainable development. Being able to preserve - where I come from, Africa, we have the wildlife there. I guess you rather preserve the wildlife, the environment for those, those people of the future, preserve for the future.

Tim: I like to think sustainability is insuring that you have enough productive assets in place to maintain or to expand the amount of output you're looking to get.... I mean, we can go and woodchip all the forest we like, but you know... And we can plant seeds behind it, but it's going to be another 20, 30 years, 40 years until those seeds mature. And if, if we can't maintain a balance ... I think it'll have 
resounding effects over the next 60 to 100 years. Well, again it's, it's going to be very important because essentially, without managing resources optimally, and effectively, and without being able to reuse those resources, I mean, it's one generation that'll benefit and then every generation afterwards will, you know, suffer the consequences, you know, of our greed.

Each of these quotes includes some aspect of the idea of justice between generations in any discussion about sustainability.

We stated earlier that the outcome of a phenomenographic investigation is a set of logically related categories - qualitatively different ways of looking at the phenomenon under investigation. As often in such 'outcome spaces', the conceptions of sustainability that we have identified are hierarchical and inclusive, both logically and empirically. Logically, the broadest conception of sustainability in terms of justice contains the more limited conception in terms of resources, and this in turn may contain the narrowest conception in the form of a definition. Empirically, we can see that those students who discuss the justice aspects of sustainability often situate this in terms of the resources that should be looked after (as Tim's quote illustrates), and students who talk about sustainability in terms of resources may also propose a definition of sustainability (as Erica does at the beginning of her quote). However, this inclusivity is one way: those students who express a distance view of sustainability don't seem to show familiarity with the broader conceptions. Indeed, this is why as educators we favour the broadest conception, as it allows students access to the whole range of ideas about sustainability, while the narrowest conception limits students to rather simplistic and even dubious definitions of the notion.

\section{Discussion}

While it is true to say that the business students showed a range of different ways of engaging with sustainability, many of them did so at the narrowest 'distance' level, fewer at the intermediate 'resources' level, and very few at the broadest 'justice' level (though we are not seeking to draw any conclusions from frequencies in this relatively small study). The complete range of views shown by our participants covers the generally accepted views of sustainability-ecological, social, economic, personal—as shown for example in the first chapter of the recent book edited by Docherty et al. [8]. The focus on business students was deliberate, given the important role that business and economic activity generally play in operationalising the notions of sustainability and sustainable development, and maybe in contributing to the problems. Tovey [32] writes: "From any perspective other than that of profit, it can be hard to find any 'rationality' in the ways in which our contemporary world organises its work on and uses of nature" (p. 15). However, the fact that the most common view of sustainability was the narrowest 'distance' view (illustrated in the earlier quotations) is problematic for the general development of 'sustainability literacy'.

This fact provides an enormous challenge to educators and workplaces grappling with the ways in which they can introduce sustainability and sustainable development as a pedagogical concept and as a concept at work. The group of students in our study was not part of a group that had experienced pedagogy that emphasised sustainability as a core value, but rather, their experience was somewhat more on the periphery of education for sustainability. Tertiary students in some disciplines, such as environmental studies, may be more likely to be able to talk about sustainability in a coherent and 
sophisticated way. However, most university level students are undertaking degrees where sustainable development is not a core concept but is dealt with en passant alongside a range of other 'generic skills'. It is interesting, however, that students in this cohort generally viewed sustainability in the context of the studies they were undertaking. This is most clearly illustrated by students (such as Fred) who suggested that the notion of sustainability could be used to obtain a business advantage. From this study we could postulate that disciplinary difference, and the extension into different future work environments for students, may provide different orientations to sustainability that mirror the core values of that particular area.

Indeed, this is an area that has the potential for further research. From this study we can see that the disciplinary context suggested a particular way of thinking about sustainability and working professionally with it. Studies with students from different areas, from physics or chemistry, to history and philosophy, may highlight the contribution of those areas in developing a richness of approaches to sustainability. Research with groups outside formal learning situations (such as the recent research undertaken by Podger [33] on the contribution of faith organizations for sustainable development) suggests that context plays a critical role in the development of people's values and actions towards sustainability.

This leads us to discuss the pedagogical aspects of our findings. Although the notion of sustainability makes an appearance in the lists of 'graduate attributes' from many universities, and despite the fact that we are in the middle of the United Nations Decade of Education for Sustainable Development, it seems that sustainability is not often discussed in depth with students (at least in the Australian context). Based on the outcomes of this research study, we and colleagues have been preparing workshop materials that incorporate the range of views regarding sustainability and sustainable development. Such a workshop was held at Macquarie University earlier this year [34], allowing a group of high-achieving business students from across the country to investigate the notion of sustainability (as well as other 'generic skills' — critical thinking, teamwork and ethics) in the context of a business leadership course. In the workshop, the three conceptions of sustainability were introduced, and students discussed and used them in a variety of case studies and problem contexts. Feedback from participants indicated a keen interest in ideas of sustainability but revealed a general lack of educational experience with the concept. Likewise, in our research study, only a few participants had discussed notions of sustainability in their classes and some of them gave standard 'definitions' of the concept. However, most students seemed unaware of such definitions, and in any case an essential understanding of sustainability and its implications for business practice goes far beyond the knowledge of a definition. Incorporating sustainability into education has goals that are much deeper.

The evidence provided by this study shows that there are quite different understandings of the concept of sustainability at play amongst students in higher education. These students are in contact with lecturers who also seem to display a similarly diverse range of views [9] from the most limiting to the broadest, though again the broadest views are less common. If the aims of the Decade for Sustainable Development are to be realised, then it would seem prudent to focus on both teacher and student understanding in the context of their own disciplines. Sustainability is an essential aspect of higher education, not an 'optional extra': one of our student respondents put it this way: 
Emma: For me sustainability is about sort of building yourself and your environment to make sure that there's a tomorrow and a tomorrow after that. And so it's, I wouldn't narrow it down to just, for example my abilities, my professional abilities but personally as well. And not just about my future but community at large as well. So it's just about sort of building for the future and not just for today.

\section{Acknowledgement}

The research on which this paper is based was funded by a grant from the World Bank/Global Development Network's Asia-Pacific Education Policy Research Initiative administered by the Korean Educational Development Institute (details online at http://eng.kedi.re.kr/).

\section{References and Notes}

1. UNESCO Education for Sustainable Development Website. Available online: http://portal.unesco.org/education/en/ev.php-URL_ID=27234\&URL_DO=DO_TOPIC\&URL_ SECTION=201.html (accessed August 12, 2009).

2. United Nations. Report of the World Summit on Sustainable Development, 2002. Available online: http://daccessdds.un.org/doc/UNDOC/GEN/N02/636/93/PDF/N0263693.pdf?OpenElement (accessed August 12, 2009).

3. UK Government. Securing the Future - UK Government Sustainable Development Strategy, 2005. Available online: http://www.defra.gov.uk/sustainable/government/publications/ukstrategy/documents/SecFut_complete.pdf (accessed August 12, 2009).

4. Orr, D.W. Four challenges of sustainability. Conserv. Biol. 2002, 16, 1457-1460.

5. Sterling, S. Sustainable Education: Re-visioning Learning and Change; Green Books: Dartington, UK, 2001.

6. Curran, M. Wrapping our brains around sustainability. Sustainability 2009, 1, 5-13.

7. Ansari, W.; Stibbe, A. Public health and the environment: what skills for sustainability literacyand why? Sustainability 2009, 1, 425-440.

8. Docherty, P., Kira, M, Shani, A., Eds. Creating Sustainable Work Systems, 2nd ed.; Routledge: London, UK, 2009.

9. Reid, A.; Petocz, P. University lecturers’ understanding of sustainability. Higher Educ. 2006, 51, 105-123.

10. Maiteny, P. Education for sustainability and development: psycho-emotional blocks and catalysts. Develop. Educ. J. 2005, 11, 1-4.

11. Abrandt Dahlgren, M.; Reid, A.; Dahlgren, L.O.; Petocz, P. Learning for the professions: lessons from linking international research projects. Higher Educ. 2007, 6, 129-148.

12. Marton, F.; Booth, S. Learning and Awareness; Lawrence Erlbaum: Mahwah, NJ, USA, 1997.

13. Boyatzis, R. Transforming Qualitative Information: Thematic Analysis and Code Development; Sage Publications: Thousand Oaks, CA, USA, 1998.

14. Strauss, A., Corbin, J., Denzin, N., Lincoln, Y., Eds. Handbook of Qualitative Research. Sage Publications: Thousand Oaks, CA, USA, 1994; pp. 273-285. 
15. Fien, J.; Tilbury, D. The global challenges of sustainability. In Education and Sustainability: Responding to the Global Challenge; Tilbury, D., Stevenson, R., Fien, J., Schreuder, D., Eds.; IUCN Commission on Education and Communication: Gland, Switzerland, 2002; pp. 1-12.

16. Meyer, J.H.F.; Land, R. Threshold concepts and troublesome knowledge (2): epistemological considerations and a conceptual framework for teaching and learning. Higher Educ. 2005, 49, 373-388.

17. Bruce, C.; Gerber, R. Towards university lecturers' conceptions of student learning. Higher Educ. 1995, 29, 443-458.

18. Prosser, M.; Trigwell, K. Perceptions of the teaching environment and its relationship to approaches to teaching. Br. J. Educ. Psychol. 1997, 67, 25-35.

19. Hazel, E.; Prosser, M. First-year university students' understanding of photosynthesis, their study strategies and learning context. Amer. Biol. Teach. 1994, 56, 274-279.

20. Davies, A.; Reid, A. Uncovering problematics in design education: learning and the Design Entity. In Proceedings of the International Conference of Re-Inventing Design Education in the University, Perth, Australia, December 2000; Swann, C., Young, E., Eds.; School of Design, Curtin University: Perth, Australia, November 2001; pp. 178-184.

21. Reid, A.; Petocz, P. Students' conceptions of statistics: a phenomenographic study. J. Statist. Educ. 2002, 10; Available online: http://www.amstat.org/publications/jse//v10n2/redi.html (accessed August 12, 2009).

22. Reid, A.; Petocz, P.; Smith, G.H.; Wood, L.N.; Dortins, E. Maths students' conceptions of mathematics. N. Z. J. Math. 2003, 32, 163-172.

23. Loughland, T.; Reid, A.; Petocz, P. Young people's conceptions of environment: a phenomenographic analysis. Environ. Educ. Res. 2002, 8, 187-197.

24. Petocz, P.; Reid, A.; Loughland, T. The importance of adults' conceptions of the environment for education. In Australian Association for Research in Education 2003 Conference Papers, Auckland, New Zealand, December 2003; Jeffery, P.L. Ed.; AARE. Available online: http://www.aare.edu.au/03pap/pet03250.pdf (accessed August 12, 2009).

25. Wihlborg, M. Teachers' understanding of internationalisation as an essential part of nursing education in Sweden. Eur. Educ. Res. J. 2003, 2, 322-341.

26. Wihlborg, M. Student nurses' conceptions of internationalisation in general and as an essential part of Swedish nurses' education. Higher Educ. Res. Dev. 2004, 23, 433-454.

27. Sin, S.; Reid, A.; Jones, A. Student conceptions of accounting work in practice. Account. Educ. (in review).

28. Sin, S.; Reid, A.; Dahlgren, L.O. The conceptions of work in the accounting profession in the $21^{\text {st }}$ century from the experiences of practitioners. In Proceedings of The $6^{\text {th }}$ International Conference on Researching Work and Learning; Roskilde University, Roskilde, Denmark, June 2009.

29. Bowden, J. Phenomenographic research-some methodological issues. In Reflections on Phenomenography; Dall'Alba, G., Hasselgren, B., Eds.; Göteborg Studies in Educational Sciences 109: Göteborg, Sweden, 1996; pp. 49-66.

30. Dortins, E. Reflections on phenomenographic process: interview, transcription and analysis. In Quality Conversations, Proceedings of HERDSA Conference; Perth, Australia, July 2002; 
Available online: http:/www.herdsa.org.au/newsite/wp/wp-content/uploads/conference/2002/ papers/Dortins.pdf (accessed August 12, 2009).

31. Reid, A.; Petocz, P.; Braddock, R.; Taylor, P.; McLean, K. Professional Formation: Exploring Students' Understanding of Creativity, Sustainability, Ethics and Cross-Cultural Sensitivity. AP-EPRI KEDI: Korea, 2006. Available online: http://eng.kedi.re.kr (accessed August 12, 2009).

32. Tovey, H. Sustainability: a platform for debate. Sustainability 2009, 1, 14-18.

33. Podger, D. Contribution of a Faith Organisation to Education for Sustainability: Infusing Spirituality into Learning for Sustainability. Doctoral Thesis. Macquarie University: Sydney, Australia, 2009.

34. EDDGS. Embedding the Development and Grading of Generic Skills in the Business Curriculum. Available online: http://www.graduateskills.com/ (accessed August 12, 2009).

(C) 2009 by the authors; licensee Molecular Diversity Preservation International, Basel, Switzerland. This article is an open-access article distributed under the terms and conditions of the Creative Commons Attribution license (http://creativecommons.org/licenses/by/3.0/). 